\section{Cobertura universal de saúde: como misturar conceitos, confundir objetivos, abandonar princípios}

\author{
Universal health coverage: how to mix concepts, \\ confuse objectives, and abandon principles \\ Cobertura universal de salud: cómo mezclar \\ conceptos, confundir objetivos, abandonar \\ principios
}

\footnotetext{
${ }^{1}$ Instituto de Comunicação e Informação Científica e Tecnológica em Saúde Fundação Oswaldo Cruz, Rio de Janeiro, Brasil.

Correspondência J. C. Noronha Instituto de Comunicação e Informação Científica e Tecnológica em Saúde, Fundação Oswaldo Cruz. Av. Brasil 4365, Rio de Janeiro, $R J$

21045-900, Brasil. noronha@cict.fiocruz.br
}

O Relatório Mundial de Saúde de 2010 da Organização Mundial da Saúde (OMS), Financiamento dos Sistemas de Saúde: O Caminho para a Cobertura Universal 1, poderia ser mais um relatório declaratório, com um conjunto de boas intenções, como muitos outros, não fora o interesse alargado que a proposição "cobertura universal" despertou em círculos do pensamento conservador da saúde, de defensores do "mercado" na prestação de serviços, fundações que atuam na arena da Saúde Global, como a Fundação Rockfeller, até a prestigiosa revista inglesa de Medicina, o Lancet. Esta publicou um conjunto de artigos sobre o tema, um dos quais dizia que "cobertura universal de saúde" corresponderia a uma "terceira transição sanitária global" 2. Em dezembro de 2012, o tema foi levado à Assembleia Geral da Organização das Nações Unidas (ONU) e incorporado como um dos itens da Resolução A/RES/67/81 - Saúde Global e Política Externa.

Não cabe aqui aprofundar o debate sobre a questão do direito à saúde. Ainda sob o calor das cinzas da grande calamidade que foi a Segunda Guerra Mundial, a criação da ONU, da OMS e a Declaração Universal dos Direitos Humanos representaram sinais importantes de uma vontade coletiva de renúncia à barbárie e a busca de padrões de convivência e coesão social em que o uso da força pudesse ser minimizado.
O direito à saúde ficou claramente expresso na Constituição da OMS, ao proclamar que "gozar do melhor estado de saúde que é possível atingir constitui um dos direitos fundamentais de todo o ser humano, sem distinção de raça, de religião, de credo político, de condição econômica ou social".

A Constituição Federal brasileira de 1988 incorporou em seu texto o direito à saúde como direito de todos e considerou sua garantia como dever do Estado, "mediante políticas sociais e econômicas que visem à redução do risco de doença e de outros agravos e ao acesso universal e igualitário às ações e serviços para sua promoção, proteção e recuperação".

A proclamação como direito de todos, na forma da Constituição Federal brasileira, ou sem "distinções", no enunciado da OMS, introduz de imediato a questão da equidade e da justiça tanto no gozo da saúde quanto no acesso às ações e serviços de saúde.

Segundo a Diretora Geral, o relatório de 2010 foi elaborado "em resposta a uma necessidade, expressa tanto por países ricos como pobres, de indicações práticas sobre modos de financiar os cuidados de saúde. O objetivo era transformar a evidência, recolhida de estudos em diversos locais, num menu de opções para angariar recursos suficientes e remover barreiras financeiras ao acesso, especialmente para os pobres". E, pouco adiante, 
ressalta a urgência do tema: “... neste momento caracterizado simultaneamente pela crise econômica e custos crescentes dos cuidados de saúde, à medida que a população envelhece, as doenças crônicas aumentam, e novos tratamentos mais caros se tornam disponiveis". E "Num tempo de dinheiro escasso, o meu conselho aos países é este: antes de cortarmos nas despesas em saúde, procuremos primeiro as oportunidades para aumentar a eficiência" 1.

A primeira referência explícita à "cobertura universal” pela OMS aparece em um dos relatórios para a 58 Assembleia Geral, em 2005, intitulado Seguro Social de Saúde: Financiamento Sustentável da Saúde, Cobertura Universal e Seguro Social de Saúde. Nele, tem início a transformação semiótica do direito à saúde e do acesso universal e igualitário aos cuidados de saúde para o conceito de "cobertura universal" indelevelmente associado à "proteção do risco financeiro" e à busca de mecanismos alternativos de financiamento setorial.

No relatório de 2010, a ordem das expressões é invertida finalmente, e o tema central passa a ser o do financiamento setorial como "caminho para a cobertura universal". E na abertura da $65^{\mathrm{a}}$ Assembleia Mundial de Saúde, a Diretora-Geral da OMS proclama: "universal health coverage is the single most powerful concept that public health has to offer" 3.

A mensagem da OMS contida no relatório de 2010 prossegue, enfatizando os determinantes da situação de saúde: "As 'circunstâncias em que as pessoas crescem, vivem, trabalham e envelhecem' influenciam fortemente como as pessoas vivem e morrem. Reduzir as desigualdades nestas áreas irá reduzir as desigualdades em saúde".

E a cobertura universal: “... os Estados Membros da Organização Mundial da Saúde comprometeram-se em 2005 a desenvolver sistemas de financiamento da saúde, que permitam às pessoas aceder a serviços sem enormes sacrifícios financeiros para pagá-los. Esta meta foi definida como cobertura universal, por vezes também chamada cobertura universal de saúde".

A primeira referência faz alusão ao relatório da Comissão dos Determinantes Sociais da Saúde ${ }^{4}$, que trouxe à tona aqueles condicionantes da situação de saúde de impacto maior do que os resultantes da prestação de cuidados de saúde. Para garantir o direito à saúde é preciso examinar os diferentes processos em curso nos países relacionados ao emprego e renda, educação, habitação, saneamento e ambiente, alimentação, reforma agrária, desenvolvimento social, entre outros. Como regra geral, as inversões e serviços de interesse coletivo são financiados por impostos, contribuições e taxas que integram os orçamen- tos dos governos em seus diferentes níveis. A destinação final dos fundos desse pool de recursos fiscais arrecadados está descrita nos orçamentos e planos de investimento, nos quais as decisões são explicitadas: tanto para a defesa, a educação, a saúde quanto para pagamento de juros e encargos de dívida, e assim por diante. Essa digressão visa a demonstrar a fraqueza do argumento de que uma política específica para se concretizar deve merecer um mecanismo de pooling específico. As intervenções dos poderes públicos se dão por poolings de impostos, contribuições e taxas! Ademais devemos examinar sua expressão tanto do lado da apropriação de recursos da sociedade pelas vias fiscais (justiça fiscal) quanto do lado da destinação desses recursos arrecadados (justiça distributiva). A questão dos serviços de saúde, se de interesse coletivo e financiados com recursos públicos, não deveria se submeter a regras e análises diferentes.

\section{A cobertura universal}

O termo "cobertura" classicamente expressa o alcance de uma medida sanitária como, por exemplo, a proporção de gestantes que fizeram prénatal. Há uma associação com o cumprimento da prestação, com seu acesso e uso. Outra utilização do termo corresponde a uma possibilidade de obter a prestação. Essa possibilidade pode ou não se realizar, seja pela abstenção do direito de usar, seja pela incapacidade de se obter a prestação desejada. No caso dos cuidados de saúde, ao se dizer que uma determinada unidade "cobre" um determinado número de indivíduos não significa que aquele número de indivíduos esteja utilizando os serviços da unidade ou será capaz de usá-los quando necessitar. Cobertura, portanto, difere de acesso e utilização. Quando se fala de cobertura universal sem qualificação comete-se um grande equívoco, pois pode-se admitir que a "cobertura" contributiva a um seguro social ou privado sempre corresponderá a oportunidades de acesso e uso, o que não é verdadeiro. Se aceitarmos "cobertura" como "acesso e uso oportuno a serviços efetivos e de qualidade quando necessários", o problema desaparecerá. Cobertura deve significar acesso e uso, e não apenas entitlement, que deve se dar sem barreiras.

Há muitas barreiras ao acesso, seja do lado da demanda, seja do lado da oferta ${ }^{5}$. Certamente a "barreira financeira" constitui uma barreira significativa do lado da demanda, mas não é a única e nem sempre a principal. Ela varia de acordo com o serviço necessário para atender a necessidades específicas. Ademais, por que vender a ideia de poolings dedicados como ideia central 
para o financiamento de cuidados à saúde? Se existem "determinantes sociais da saúde", por que criar poolings ou contribuições específicas para os cuidados à saúde e não para cada uma das políticas correspondentes à extensa listagem de "determinantes"? Contribuições a seguros privados, sabidamente seletivos e subsidiados, integrariam esses poolings? Há ou não "subtexto" nesse texto?

Finalmente, como última referência ao relatório: por que a questão da equidade é lançada como subalterna à ideia de "proteção financeira" dos pobres? Estranhamente, os postuladores do conceito supostamente inovador da "cobertura universal" passam ao largo do gravíssimo problema da segmentação da oferta de acordo com as classes sociais e o tipo de proteção garantido pelas diferentes modalidades de seguros públicos ou privados. Segmentação na "cesta" e na qualidade dos cuidados garantidos.

Talvez as conclusões do encontro em Bellagio, promovido pela Fundação Rockfeller, inti- tulado Future Health Markets ajude a esclarecer a força da proposta de "Cobertura Universal" em oposição a "Sistemas Universais de Saúde": "é provável que fortes agentes de mercado, como fabricantes de produtos farmacêuticos, organizações hospitalares, associações de provedores $e$ companhias de seguros, aumentem a pressão para atrair financiamento público e privado, especialmente nos países de renda baixa e média, para que adotem políticas para financiar o seguro de saúde, como um meio em direção à Cobertura Universal de Saúde (UHC)” 6.

Estaremos com "o mais poderoso conceito que a saúde pública pode oferecer" 3, caminhando aceleradamente para transformarmos a saúde humana em mercadoria e liquidar o princípio de que as necessidades de saúde e não a capacidade de pagar os serviços ou contribuir para fundos específicos é que deve presidir o acesso e uso dos mesmos?
A versão em inglês deste texto está disponível online no Portal SciELO (http://www.scielo.br/csp).

The English version of this text is available online in the SciELO (http://www.scielo.br/csp).

La versión en Inglés de este texto está disponible en línea en el SciELO (http://www.scielo.br/csp).
1. Organização Mundial da Saúde. Financiamento dos sistemas de saúde: o caminho para a cobertura universal. Relatório mundial de saúde. Genebra: Organização Mundial da Saúde; 2010.

2. Ferranti D, Rodin J. Universal health coverage: the third global health transition? Lancet 2012; 380:861-2.

3. Chan M. Best days for public health are ahead of us. Address to the Sixty-fifth World Health Assembly 2012. http://www.who.int/dg/speeches/2012/ wha_20120521/en/index.html (acessado em 20/ Mar/2013).

4. Organização Mundial da Saúde. Redução das desigualdades no período de uma geração. Igualdade na saúde através da ação sobre os seus determinantes sociais. Relatório final da Comissão para os Determinantes Sociais da Saúde. Genebra: Organização Mundial da Saúde; 2010.

5. Jacobs B, Ir P, Bigdeli M, Annear PL, Van Damme W. Addressing access barriers to health services: an analytical framework for selecting appropriate interventions in low-income Asian countries. Health Policy Plan 2012; 27:288-300.

6. Rockefeller Foundation. Future healtp:th markets: a meeting statement from Bellagio. http://www. futurehealthsystems.org/storage/publications / project-docs/bellagio-future-health-marketsstatement-final.pdf (acessado em 20/Mar/2013).

Recebido em 20/Mar/2013

Aprovado em 26/Mar/2013 